\title{
Design and Losses Analysis of a High Power Density Machine for Flooded Pump Applications
}

\author{
Ahmed Al-Timimy*, Paolo Giangrande*, Michele Degano*+, Zeyuan, Xu*, Michael Galea*+, \\ Chris Gerada*+, Giovanni Lo Calzo , He Zhang ${ }^{+}$, Liqun Xia
}

\begin{abstract}
This paper describes the design process of a $10 \mathrm{~kW}$ 19000 rpm high power density surface mounted permanent magnet synchronous machine for a directly coupled pump application. In order to meet the required specifications, a compact machine, with cooling channels inside the slots and flooded airgap, has been designed through finite element optimization. For high power density, high speed machines, an accurate evaluation of the power losses and the electromechanical performance is always extremely challenging. In this case, the completely flooded application adds to the general complexity. Therefore this paper deals with a detailed losses analysis (copper, core, eddy current and mechanical losses) considering several operating conditions. The experimental measurements of AC copper losses as well as the material properties (BH curve and specific core losses), including the manufacturing process effect on the stator core, are presented. Accurate 3D finite element models and computational fluid dynamics analysis have been used to determine the eddy current losses in the rotor and windage losses respectively. Based on these detailed analysis, the no load and full load performance are evaluated. The experimental results, on the manufactured prototype, are finally presented to validate the machine design.
\end{abstract}

Index Terms-High power density, high speed, losses calculation, performance analysis, permanent magnet motors.

\section{INTRODUCTION}

$\mathrm{I}$ ntegrated pump driven motors are widely used in aerospace electrical hydraulic actuators where reliability and size are critical. The main benefits of having a motor directly coupled to the pump are the elimination of the shaft seals and the potential improvement in the thermal rating of the machine. Removing shaft seals results in a reduction in the risk of oil leakages, while the thermal improvement comes from the fact that the coolant (oil in the case at hand) in the pumping system can be also be used to cool the electrical machine itself. Various examples of this concept in terms of electro hydraulic actuators (EHA) can be found in literature [1-3]. This paper deals with such an integrated system and focuses on the design and development of the required electrical machine.

This is the updated version of the paper that was presented at the IEEE International Conference on Electrical Machines, ICEM, 2016.

Ahmed Al-Timimy*, Paolo Giangrande*, Michele Degano*+, Zeyuan $\mathrm{Xu}^{*}$,Giovanni Lo Calzo, Michael Galea*, Chris Gerada ${ }^{*+}$ are with the Power Electronics, Machines and Control Group, the University of Nottingham, Nottingham, UK. He Zhang is with the PEMC Group, the University of Nottingham Ningbo China, Ningbo, China. Michele Degano, Michael Galea and Chris Gerada are also with the PEMC Group the University of Nottingham Ningbo China, Ningbo, China.

Liqun Xia is with the AVIC Flight Automatic Control Research Institute, Xi'an China.

Ahmed Al-Timimy (e-mail: Ahmed.Al-Timimy@nottingham.ac.uk)
Considering that the machine is directly coupled to the load (the pump), then no mechanical gear-boxes are present which improves the reliability and component-count figures of the system. However, this also means that no mechanical advantage is present in the system indicating the need for a high power density, high speed and very robust electrical machine.

\section{A. Existing works}

For the application under study, a permanent magnet synchronous motor (PMSM) has been identified as the optimal candidate due to its high power density, low inertia, and overall drive size [4-6]. In addition, PMSMs reveal small windage losses when compared to other machine topologies $[4,7]$. While the design of PMSMs is covered extensively in literature, only a limited number of works detail and discuss the development of high power density PMSMs for directly coupled pump applications that comprise a flooded airgap. The design of a high performance interior permanent magnet machine rated at $46.6 \mathrm{~kW}, 1500 \mathrm{rpm}$ for a hydraulic motor-pump application is discussed in [8]. In this work, the electrical machine is fully immersed into oil to have a compact design and efficient cooling system. A $16 \mathrm{~kW}, 15000 \mathrm{rpm}$, four-phase, fault tolerant PMSM for fuel pump drive applications is described and prototyped in [9]. This work claims that the best compromise between fault tolerance, compactness, low weight and general drive system complexity was achieved. In [10], the power losses analysis of a $100 \mathrm{~kW}, 20000 \mathrm{rpm}, 6$ poles, four phases, PMSM fault tolerant drive for pump applications is investigated and very important suggestions for improving the efficiency are provided. In [11], a $150 \mathrm{~W}, 6000 \mathrm{rpm}$ high performance pump application with low rotating inertia has been developed using surface mounted PMSM.

\section{B. Proposed work}

All the above works focus a lot of effort on the design process of the electrical machine. With the exception of [10], no detailed analysis of the losses and their effects on the machine and the system performance is given. However, for such systems were the electrical machine is usually pushed to the limit, in order to reach the required performances with no mechanical advantages, then an excellent understanding of these losses is required. This knowledge can then be translated into design processed that will allow the machine designer to improve ever more the thermal and magnetic limits of the machine and thus of the whole system.

Thus, this paper (after having presented an appropriate design process for the application) focuses on a full 
characterization and understanding of the losses and their effects on the performance characteristics of the high power density PMSM. A special focus is given to the AC copper losses and to the eddy current losses (especially in the rotor), which for such a high-speed operation can both represent a major source of losses. The paper also considers variations in the material properties and specific core losses, due to the manufacturing process on the stator core. In order to validate all the above, a prototype of the machine is built and tested. The performance comparison between the experimental and FE results, for several operating conditions, is shown and it highlight the robustness of the design process proposed in this paper.

\section{REQUIREMENTS AND CHALLENGES OF PMSM}

This section presents the design requirements and challenges associated with the PMSM used to drive an oil-flooded pump for a harsh environment application. The set of requirements is tabulated in Table I, while Fig. 1 illustrates the operating regions of the machine.

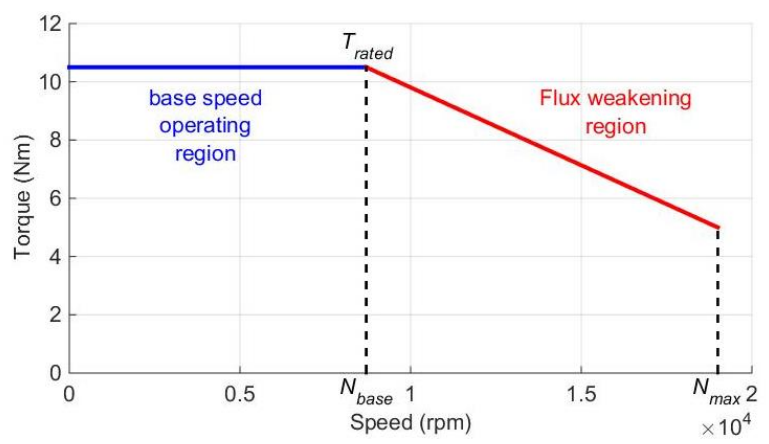

Fig. 1. Required torque-speed characteristic

TABLE I

MACHINE DESIGN REQUIREMENTS AND PERFORMANCE INDICATORS

\begin{tabular}{lc}
\hline \hline Requirements & Values \\
\hline Maximum speed & $19000 \mathrm{rpm}$ \\
Dc link voltage & $270 \mathrm{Vdc}$ \\
Maximum phase current & $\leqq 85 \mathrm{~A}$ \\
THD of BEMF & $\leqq 5$ \\
Moment of inertia & $\leqq 1 \times 10^{-4} \mathrm{~kg} \cdot \mathrm{m}^{2}$ \\
Weight & $\leqq 2.5 \mathrm{~kg}$ \\
Stack length & $\leqq 85 \mathrm{~mm}$ \\
Axial cross section & $\leqq 70 \times 70 \mathrm{~mm}$ \\
Cooling method & Oil cooled \\
Maximum coolant flow rate & $4.2 \mathrm{~L} / \mathrm{min}$ \\
\hline \hline
\end{tabular}

From the above, it can be argued that the key challenges related to this particular machine design are:

1- Torque-speed characteristic

Maximum continuous torque $\left(T_{\text {rated }}\right)$ is required over a speed range from 0 to $8700 \mathrm{rpm}$. Beyond the base speed ( $\left.N_{\text {base }}\right)$ of $8700 \mathrm{rpm}$, flux weakening is required until the maximum speed $\left(N_{\max }\right)$ of $19000 \mathrm{rpm}$.

2- High power density

High power to mass and power to volume ratio are key design aspects of the application, due to the system's space constraints. The total machine mass should be less than $2.5 \mathrm{~kg}$, including all active parts.

3- Flooded machine operation
For increasing the current density of the motor and minimizing the number of the shaft seals between the motor and pump, the oil of the pumping system can be used to cool the machine. This allows much higher than typical current densities to be used. However, the flooded machine will result in higher windage losses.

4- Windage losses

The rotor is immersed in oil for cooling purpose. As the rotating velocity increases, the windage losses increase also having a direct effect on the machine efficiency.

5- Fast dynamic response

In order to ensure both fast dynamic response and high acceleration, a low moment of inertia is desirable.

\section{MACHINE DESIGN AND CONSIDERATIONS}

In previous research work [4, 12], a PMSM with 8 poles and 9 slots has been developed for the motor driven pump application after an extensive analysis, including a combined electromagnetic, thermal and mechanical design. Despite its inherent unbalanced magnetic pull (UMP), the 9 slots / 8 pole combination has been preferred due to its superior performance in terms of torque ripple and efficiency [4], as resulting from the trade-off study [12]. Fig. 2 shows the cross-sectional area of the designed machine.

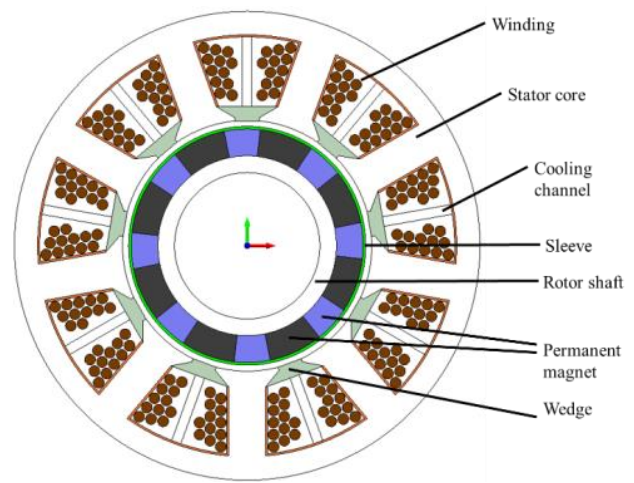

Fig. 2. Cross-section of 9s/8p PMSM.

In general, the performance of the PMSM is limited by 1) the current density generated inside the slot and 2) the maximum magnetic flux density of the teeth and back iron. Thus, for the stator core, Cobalt Iron material (CoFe) with $0.1 \mathrm{~mm}$ lamination thickness has been considered, because it has lower specific iron losses and higher magnetic saturation (2.3T) compared to the conventional silicon steel material [12-13]. By using $\mathrm{CoFe}$ material, the slot area can be made to increase by $22.3 \%$ when compared to the Silicon Steel ( $\mathrm{SiFe})$ case. The higher slot area available leads to $21.1 \%$ current density reduction [4, 12]. Considering the operating point at $1.5 \mathrm{~T}$ and $400 \mathrm{~Hz}$, the $\mathrm{CoFe}$ material allows a reduction of about $80.45 \%$ in terms of specific iron losses.

A Halbach array configuration has been adopted for the permanent magnet (PM) to maximize the airgap flux density and reduce the rotor back iron thickness. Since the rotor is flooded, a higher temperature is generated on the rotor surface, due to the friction between the oil and the rotating components. For this reason, Samarium Cobalt permanent magnets (Recoma $\left.33 \mathrm{E}\left(\mathrm{Sm}_{2} \mathrm{Co}_{17}\right)\right)$ are chosen, because of the higher operating temperatures (readily available SmCo PMs today can easily operate at $350^{\circ} \mathrm{C}$ ). 
The airgap length represents a critical parameter, since it affects both the windage losses and the amount of PM material. For this reason, a trade-off study has been performed to carefully select the airgap length value. The trade-off study has been carried out considering a rotor speed of $19 \mathrm{krpm}$ (i.e. worse condition in terms of windage losses) and a cooling oil temperature of $90^{\circ} \mathrm{C}$. By increasing the airgap length, the windage losses will decrease, as well as, the developed torque, if the amount of permanent magnet material is kept the same. Therefore, when the airgap length is changed, the amount of permanent magnet material is modified, in order to generate the desired torque.

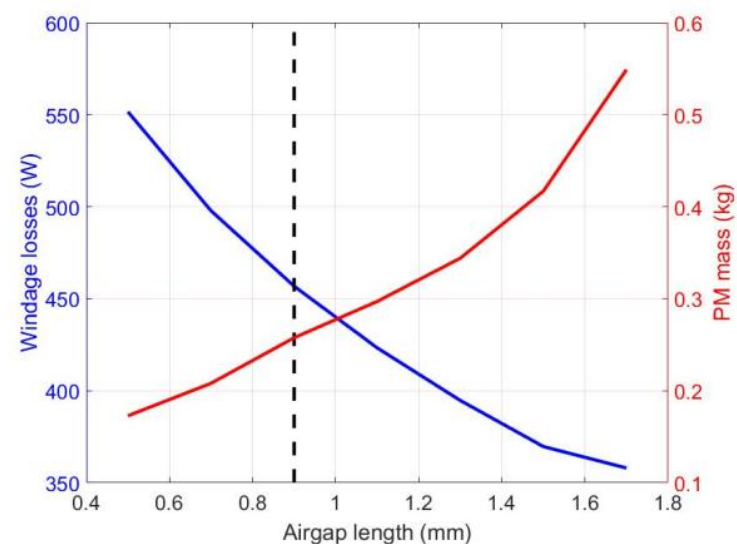

Fig. 3. Windage losses and permanent magnet mass for different airgap lengths, at $19 \mathrm{krpm}$ (torque $5 \mathrm{Nm}$ ) and $90^{\circ} \mathrm{C}$ cooling oil temperature.

The trade-off study results are summarized in Fig. 3, where the airgap length optimum value of $1 \mathrm{~mm}$ is found. In the final machine design, an airgap length value of $0.9 \mathrm{~mm}$ (black dash line of Fig. 3) has been selected, because the rotor inertia requirement was not fulfilled by using $1 \mathrm{~mm}$.

The PMs are glued to the rotor shaft and retained by a sleeve made of nonmagnetic material against the centrifugal forces [14]. The selected material for the rotor sleeve is Titanium Ti6A14V designed with a thickness of $0.4 \mathrm{~mm}$, to reduce the moment of inertia and increase the airgap width. Carbon-fiber could not be utilized mainly due to its incompatibility with the oil-based coolant used in this application.

A hollow shaft made of 17-4 PH Stainless material is designed to reduce mass and meet the moment of inertia requirement. The rotor is supported by bearings at each end, which have been selected in order to withstand the inherent UMP of the 9 slot / 8 pole combination. In particular, a deep groove ball bearing is used at the drive end, while at the nondrive end, a pair of back to back bearings is adopted for increasing the rotor stability. An internal spline coupling is designed at the drive end where the hydraulic pump is connected. Hydraulic oil from the pump flows into motor at the front of the machine housing passes through the gap and cooling channels inside the machine and flows out at the rear end. A schematic of the machine including the housing and the cooling system can be seen in Fig. 4.

The machine housing is designed to be oil flooded and oil tight with a maximum internal pressure of 20 bars. An analysis based on Computational Fluid Dynamics (CFD) was used identify the optimal internal oil flow paths and to calculate and predict temperatures distribution within the machine [5]. As can be seen from Fig. 4, a fin array is attached to the machine housing, so as to enhance the heat dissipation to air. The machine housing then serves as an additional heatsink for the whole pumping system.

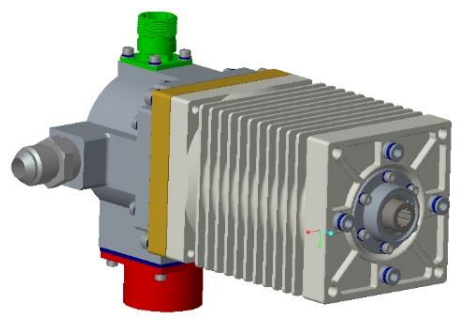

(a)

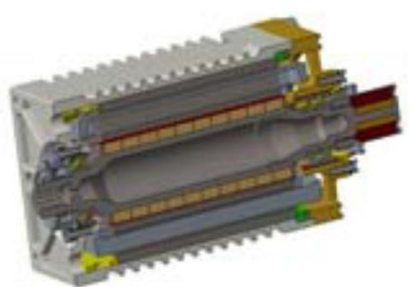

(b)
Fig. 4. 3D view of the assembled PMSM (a) Overview (b) Cross section view.

As a result of the design, the current density for the direct coupled pump motor is $27.2 \mathrm{~A}_{\mathrm{rms}} / \mathrm{mm}^{2}$, to achieve the requirements with compact machine design. For such a high current density, a very efficient oil cooling system is adopted, directly pushed through the windings [5]. Some of the more important machine performance parameters are summarized in Table II, whereas the materials used are summarized in Table III.

TABLE II

GEOMETRICAL DIMENSIONS AND PERFORMANCE INDICATORS

\begin{tabular}{lcc}
\hline \hline & $\begin{array}{c}10.5 \mathrm{Nm} @ \\
\text { Parameters }\end{array}$ & $\begin{array}{r}5 \mathrm{Nm} @ \\
19000 \mathrm{rpm}\end{array}$ \\
\hline DC link voltage (V) & \multicolumn{3}{c}{270} \\
Rated current (A) & \multicolumn{3}{c}{85} \\
Split ratio & \multicolumn{2}{c}{0.535} \\
Airgap length (mm) & \multicolumn{3}{c}{0.9} \\
Current density J $\left(\mathrm{A} / \mathrm{mm}^{2}\right)$ & \multicolumn{2}{c}{27.2} \\
Efficiency (\%) & 91.2 & \multicolumn{2}{c}{86.5} \\
Torque ripple (\%) & 0.5 & \multicolumn{2}{c}{0.8} \\
Back-EMF THD $(\%)$ & 3.13 & \multicolumn{2}{c}{3.14} \\
Moment of inertia $\left(\mathrm{kg} \cdot \mathrm{m}^{2}\right)$ & \multicolumn{3}{c}{$1 . e^{-4}$} \\
\hline \hline
\end{tabular}

TABLE III

SUMMARY OF MOTOR MATERIAL

\begin{tabular}{lc}
\hline \hline Component name & Material name \\
\hline Stator iron core & VacoFlux 48 \\
Shaft & 17-4 PH Stainless Steel \\
Permanent magnet & RECOMA 33E: (Sm2Co17) \\
Coil & Copper: 5.77e7 S/m \\
Rotor sleeve & Titanium \\
\hline \hline
\end{tabular}

\section{NUMERICAL ANALYSIS OF PMSM PERFORMANCE}

In this section, the performance of the designed PMSM is highlighted, under both no-load and full-load conditions. The finite element FE model of the investigated machine has been created using the commercial package software (Infolytica MagNet). 2D time-stepping simulations are considered during this study where a Maxwell stress tensor was used for the torque calculation. In order to evaluate the effect of the PM segmentation and the Joule losses in the end-windings, 3D FE simulations are performed.

A. No load condition 
The 2D no load flux density map of the machine is presented in Fig. 5 while, the machine back electromotive force (BackEMF) waveform at $19000 \mathrm{rpm}$ is shown in Fig. 6. The Fourier series transformation has been applied to the estimated no load line to line Back-EMF waveform. The total harmonic distortion (THD) at the maximum operating speed of $19000 \mathrm{rpm}$ are $2.09 \%$ and $2.12 \%$ for the $2 \mathrm{D}$ and $3 \mathrm{D}$ FE results, respectively.

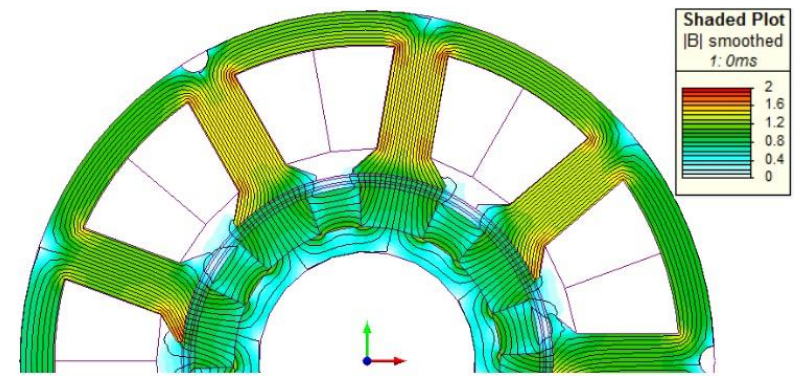

Fig. 5. No load flux density map and flux line distribution @ $19000 \mathrm{rpm}$.

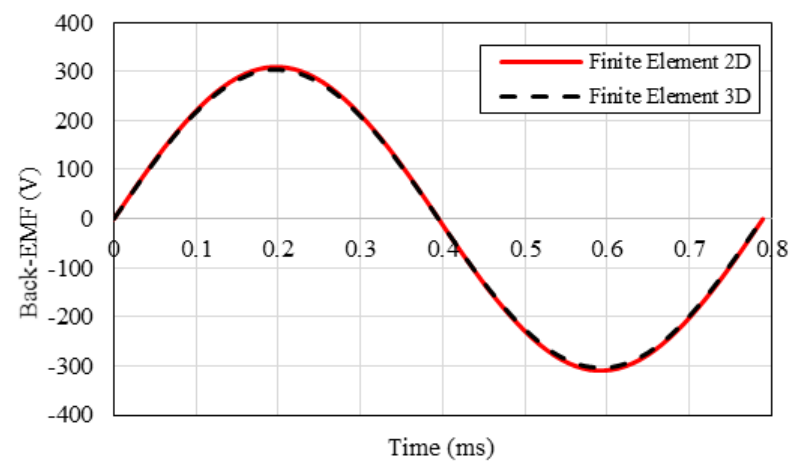

Fig. 6. No load Back-EMF @ 19000 rpm.

The voltage constant $K_{v}$ is calculated with the numerical results showing a liner relationship with respect to the mechanical speed, as illustrated in Fig. 20 (c). The $K_{v}$ is $0.022 \mathrm{Vs} / \mathrm{rad}$ using 2D FEM and $0.0216 \mathrm{Vs} / \mathrm{rad}$ using 3D FEM. Lower back-EMF amplitudes and $K_{v}$ are observed when the end-effects are included in the 3D model. This is due to the end magnet leakage which reduces both the amplitude and other order harmonics of the back-EMF (at the same rate).

\section{B. Full load condition}

The machine full load performance has been investigated to evaluate the electromagnetic torque and the torque ripple. 2D and 3D (transient with motion) simulations are considered for this analysis. The machine torque waveform at full load of $\left(I_{q}=80 \mathrm{~A}, I_{d}=0\right)$ with rated speed of $8700 \mathrm{rpm}$ is presented in Fig. 7 , as calculated by FEM analysis. The electromagnetic torque of the 2D and 3D FEM has an average of $10.52 \mathrm{Nm}$ and 10.27 $\mathrm{Nm}$, respectively. Also, the torque waveform has significantly low torque ripples $(0.97 \%$ for the $3 \mathrm{D}$ FEM and $0.8 \%$ for the $2 \mathrm{D}$ FEM) due to low cogging torque and Back-EMF total harmonic distortion. Therefore, the torque ripple difference between the 2D FEM and 3D FEM can be neglected. Also, the torque constant $K_{T}$ has been calculated where only the q-axis current is applied to the machine and the results obtained from the $2 \mathrm{D}$ model was $0.1315 \mathrm{Nm} / A$ while $0.1283 \mathrm{Nm} / A$ for $3 \mathrm{D}$ model. The flux density map for the two operating points are presented in Fig. 8 (a) and (b). All the above indicates that the machine design as presented in $[4,12]$ satisfies the requirements of the application at hand. From the numerical analyses presented above, it is perceived that the 3D FE model considers more aspects than its 2D counterpart and therefore gives a more accurate representation of the electrical machine.

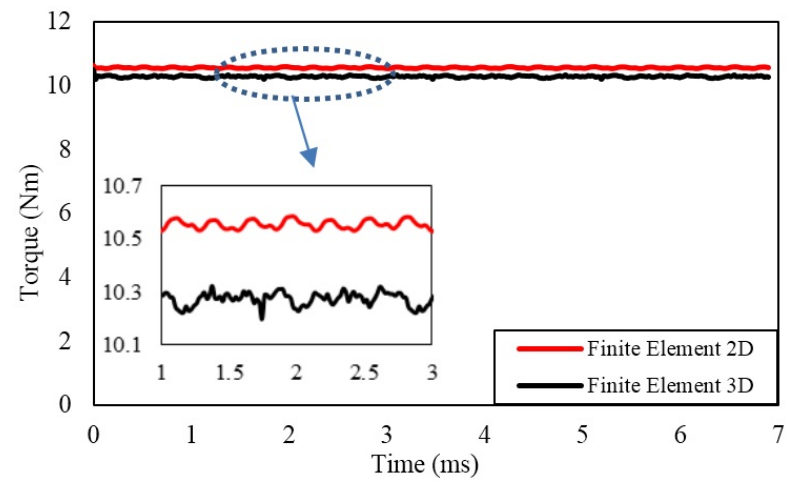

Fig. 7. Torque at full load condition @ 8700 rpm and 80 A.

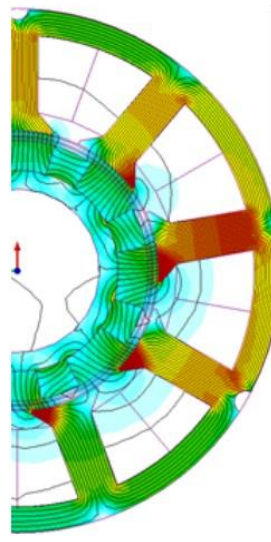

(a)

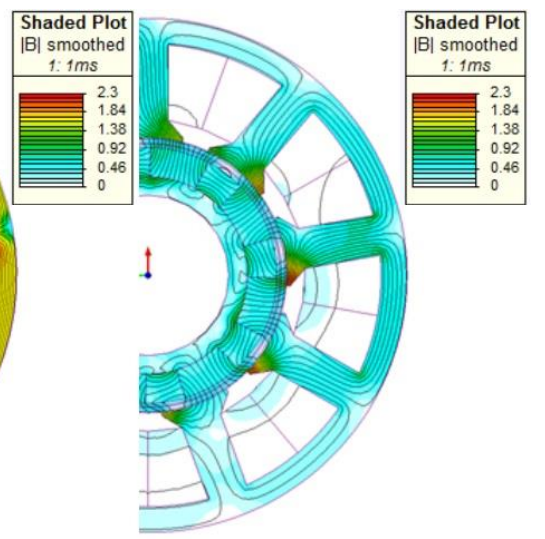

(b)
Fig. 8. Full load flux density map and flux line distribution (a) 10.5 Nm @ 8700 rpm (b) 5 Nm @ 19000 rpm.

\section{LOSSES EVALUATIONS}

As mentioned above, a main point of interest in this paper is to achieve an understanding of the loss distribution in the designed machine. The PMSM losses terms have been investigated to evaluate the motor efficiency in several operating conditions.

\section{A. Copper Losses}

In a PMSM, the total copper loss is influenced by the operating speed of the motor, since the winding resistance increases with the frequency due to the skin effect and proximity effect [15-17]. For the considered application and due to the high fundamental frequency $f$ of $1.26 \mathrm{kHz}$ at the maximum operational speed, the additional AC copper loss can have a significant effect on the machine performance. The total copper losses can be considered as the sum of two terms, namely the Joule losses in the active-length of the winding $\left(P_{a c t}\right)$ and the Joule losses in the end-winding $\left(P_{\text {end }}\right)$, as shown in (1), where $\mathrm{T}$ is temperature and $\mathrm{f}$ is frequency.

$P_{\text {tot }}(T, f)=P_{\text {act }}(T, f)+P_{\text {end }}(T, f)$

Under DC operation, the two components can be identified easily from the DC winding resistance and the total length of the winding including (active and end-winding lengths). The 
effect of the temperature on the resistance is taken into account by using (2), where, $\rho_{\mathrm{o}}$ is the electrical resistivity of copper at $T_{o}=20^{\circ} \mathrm{C}$ and $1.68 \cdot 10^{-8} \mathrm{~m} \Omega$ and $\alpha$ is the temperature coefficient of resistivity and is 0.00393 and $T$ is the operating temperature.

$\rho=\rho_{\mathrm{o}}\left(1+\alpha\left(T-T_{\mathrm{o}}\right)\right)$

However, in case of AC operation, the expression given in (2) cannot be used directly to correct the operating temperature, since, the DC and AC copper losses components vary with temperature in different manners [18].

Therefore, a 3D FE analysis is done in order to simulate the AC copper losses including the contribution of the end winding into the overall copper losses. Fig. 9 (a) shows the outline of stator core with 9 slots. Each solid conductor via an external circuit have been used to show the effect of skin and proximity effect for both active length and end-winding.

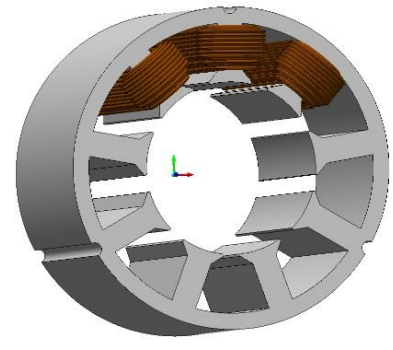

(a)

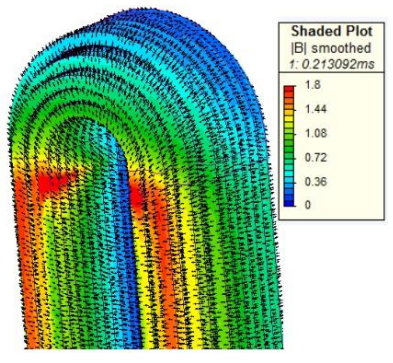

(b)
Fig. 9. 3D FE model (a) Outline of the analyzed model with winding (b) Flux density distribution in the stator winding (active length and end-winding).

Fig. 9 (b) shows the distribution of the magnetic flux density in the stator windings. The largest slot leakage flux are close to the slot opening region while, the lowest in the slot top region as confirmed in Fig. 9 (b). Therefore, the amount of ac copper losses is higher in windings placed near to the slot opening region. Also, the ratio between the $\mathrm{AC}$ and $\mathrm{DC}$ phase resistance versus frequency at working winding temperature is shown in Fig. 10. For the end-winding, the $R_{A C} / R_{D C}$ ratio is small because the leakage flux inside the active-length winding is high compared to end-winding region, where the windings are surrounded by air, as shown in Fig. 9 (b).

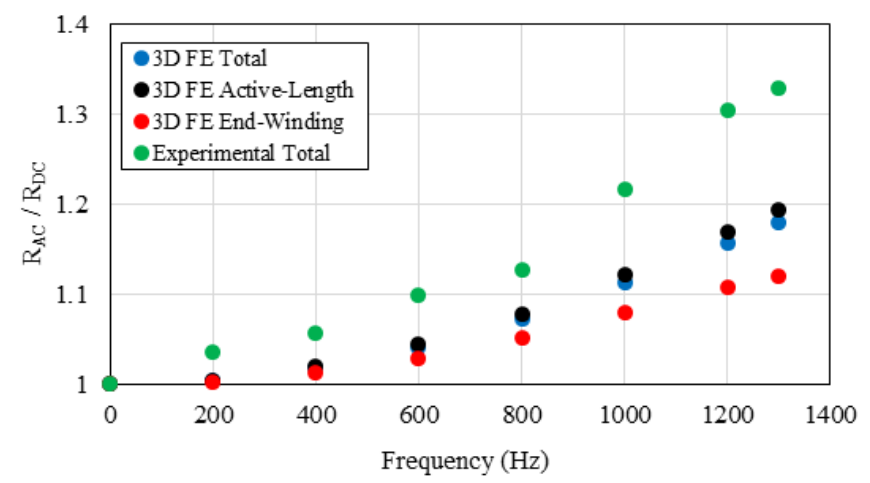

Fig. 10. $R_{a c} / R_{d c}$ ratio vs. frequency under $I_{r m s}=25 \mathrm{~A}$ at working winding temperature.

However, the AC copper losses obtained from FE simulation are not accurate enough, due to the uncertainties in the conductor distribution inside the slot. For more accurate prediction, the AC copper losses have been measured experimentally. The tests have been carried out on a complete wound stator as shown in Fig. 18 (b). A variable-frequency power supply with sinusoidal current (Chroma 61511) was used to energies the winding under test. The power, voltage and current were measured using a high bandwidth power analyzer (KinetiQ PPA2530) and therefore the changing in resistance with frequency can be determined. A number of K-type thermocouples placed within the end-winding and mid of active length of the winding were used to monitor the temperature [19]. The core losses have been subtracted from the total measured losses in order to determine the Joule losses. At $1266.6 \mathrm{~Hz}$, the $R_{A C} / R_{D C}$ ratio obtained from the experimental data is $13.67 \%$ higher than the ratio determined by using $3 \mathrm{D} \mathrm{FE}$ results as shown in Fig. 10. This mismatch is due to the random distribution of the conductors inside the slot which generate more losses than the FEM with defined position of conductors.

\section{B. Stator Core Loss}

Since, the stator core is the result of a machining processes, its magnetic properties, such as specific core losses and the magnetization $\mathrm{BH}$ curve, can change with respect to the single sheet test. These variations might affect the stator core losses and thus the machine performance, especially in case of high performance applications. For this reason, it is necessary to determine the specific core losses and the $\mathrm{BH}$ curve for the manufactured stator core to calculate accurately the machine core losses.
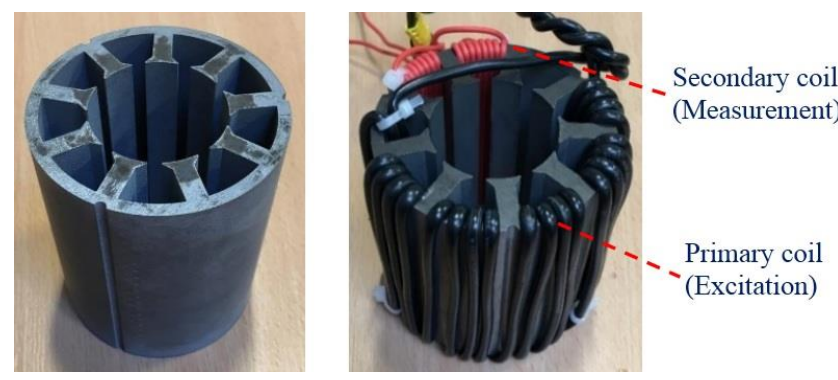

Fig. 11. CoFe material stator core (left) and wound stator under test (right).

The tested stator core is shown in Fig. 11. For the losses measurements, a state of the art testing facility, available in-house, has been used to characterize this sample [20]. The measuring system is equipped with a high-power amplifier, a digital frequency generator and a set of safety protections to ensure high accuracy and high fidelity of the tests along with high level of safety while testing. A high speed real-time software interface allows easy programming and monitoring of the experiments [20].

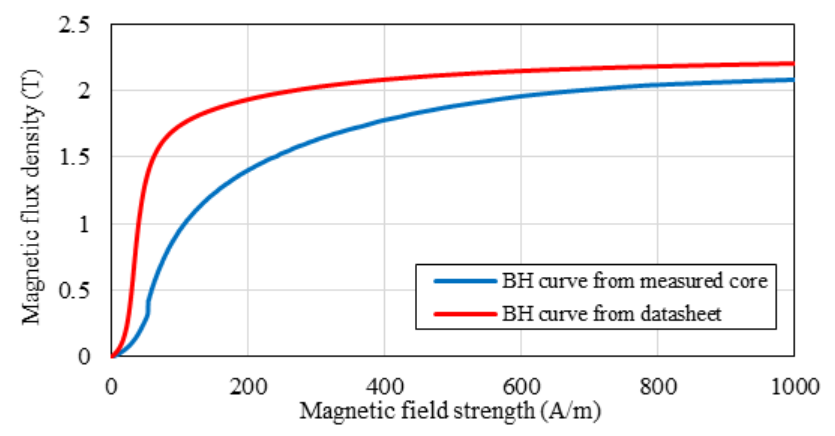

Fig. 12. Comparison among BH magnetization curves. 
The core losses tests at high frequency and high flux density for the slotted stator core are performed under pure sine wave excitation. A slotted stator core has been setup with two set of coils as shown in Fig. 11. Using this test facility, the magnetization $\mathrm{BH}$ curve and the core losses with different frequencies and different flux densities are measured. The $\mathrm{BH}$ magnetization curve for the slotted stator core is thus calculated. The obtained results are compared to the $\mathrm{BH}$ magnetization curve provided by the manufacturer, as shown in Fig. 12. Analysing the results of Fig 12, the BH curve provided by the manufacturer shows a much higher relative permeability, which if used would result in a design that promises much higher magnetic flux density.

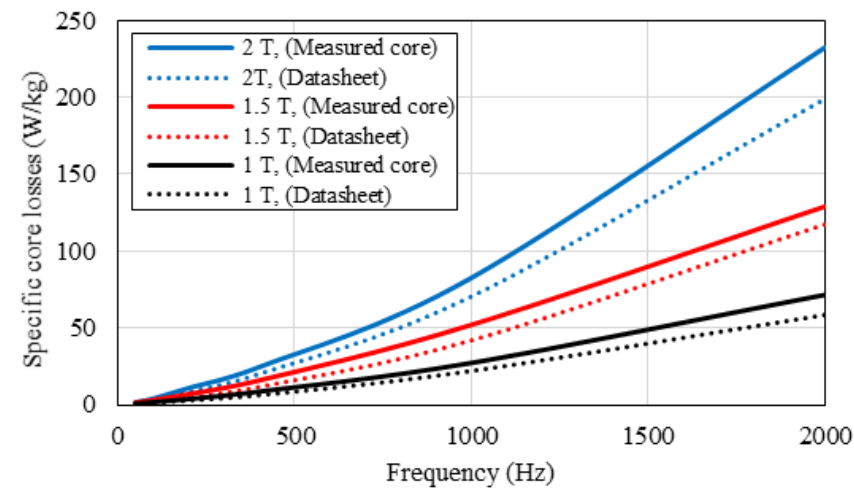

Fig. 13. Specific core loss compassion between measured stator and datasheet.

The specific core losses comparison between the measured stator core and data sheet provided by the manufacturer as a function of different frequencies and flux densities is shown in Fig. 13. As expected the increase in the core losses is proportional to the higher frequencies. As can be observed, the core loss from the measured data is higher than that given by the data sheet indicating that the manufacturing process does have an effect on the specific core losses of the material.

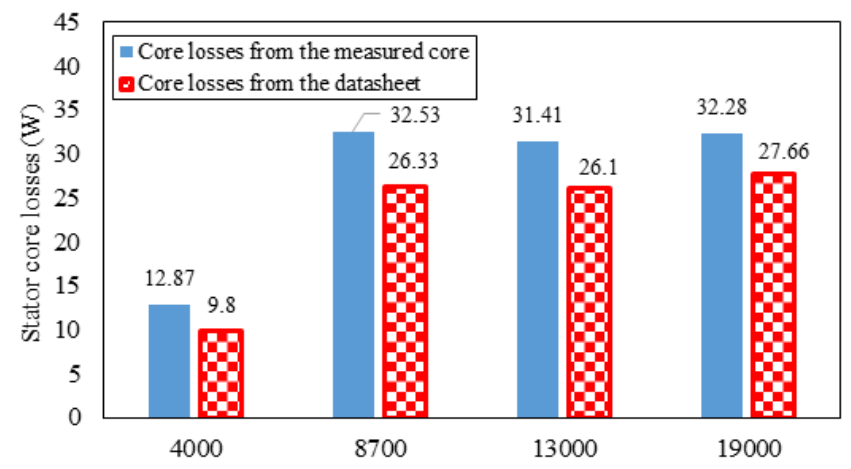

Fig. 14. Stator core loss at rated torque condition and different speeds.

To assess these variation on the machine performance, the machine is simulated with the two datasheets of material data and the results compared for different operating conditions. Under no load condition, the maximum peak value of the back EMF at different operating speeds are reported in Table IV. It can be seen that for different operating speeds the change in the no load voltage is negligible $(<1 \%)$. In Fig. 14, the core losses at full load condition and for different operating speeds are presented. As expected, a variation can be observed between the measured data and datasheet of the manufacturer with $23 \%$ difference at the rated operating point. This discrepancy is due to the deterioration of the magnetic material properties and the increased core losses during the manufacturing processes of the stator core.

TABLE IV

COMPARISON OF THE BACK-EMF AT NO LOAD CONDITION FOR DIFFERENT DATA SHEETS

\begin{tabular}{|c|c|c|c|}
\hline & & Datasheet & Measured core \\
\hline \multirow{4}{*}{ 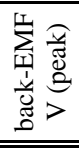 } & $4000 \mathrm{rpm}$ & 36.29 & 36.21 \\
\hline & $8700 \mathrm{rpm}$ & 78.91 & 78.73 \\
\hline & $13000 \mathrm{rpm}$ & 117.89 & 117.62 \\
\hline & $19000 \mathrm{rpm}$ & 174.41 & 173.98 \\
\hline
\end{tabular}

C. Rotor Eddy Current Losses

Eddy currents in the conductive components (i.e. magnets, retaining sleeves and shaft) are source of losses, which can be determined by (3), where $J$ is the eddy current density in a conductive volume and $\sigma$ is the material conductivity.

$P_{e d d y}=\sum_{n}\left\{\int_{v o l} \frac{\left|J_{n}\right|^{2}}{2 \sigma} d v\right\}$

At high speeds, the eddy currents inside the permanent magnets generate significant losses, which could increase the permanent magnet temperature causing demagnetization [21, 22]. In case of fractional slot PMSM with concentrated winding, this issue is more critical due to the high harmonic content of the armature field [3]. In order to improve the PMSM efficiency, the eddy current losses in the permanent magnets are reduced by adopting the segmentation of the PMs. The performance of the PMSM using magnets axially segmented is investigated by means of 3D FE simulations. Fig. 15 (a) shows the current density distribution in a magnet with 10 segments at $19000 \mathrm{rpm}$. By segmenting the permanent magnets, the eddy currents paths are reduced, since the eddy currents are constrained inside each PM single segment. Hence, a higher number of segments results in shorter paths and lower eddy currents losses.

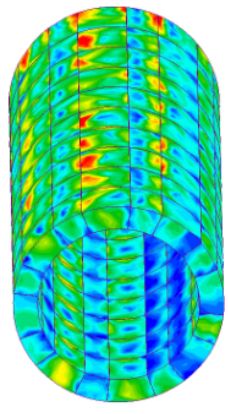

(a)

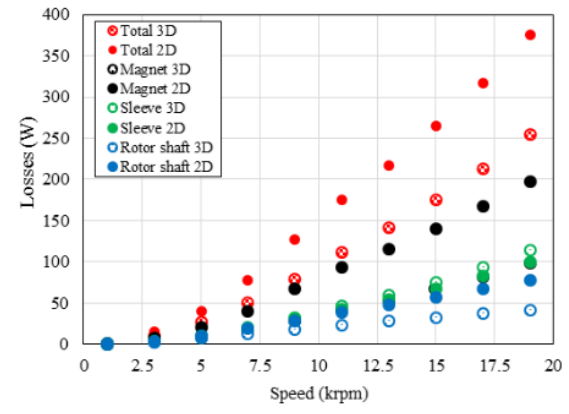

(b)
Fig. 15. Eddy current loss of 8p/9s PMSM using 2D and 3D FEM (a) In the segmented magnet at $19 \mathrm{krpm}$ (b) In magnet, sleeve and solid shaft at full load.

Adopting 10 axial segments, the eddy current losses drop by $54.7 \%$ compared to non-segmented magnet. Eddy current losses might also be generated inside both titanium sleeve and the stainless-steel shaft, due to high conductivity of these materials. Fig. 15 (b) shows the eddy current losses in sleeve, shaft and magnets, for several speeds at full load condition. Lower eddy losses are observed when the end-effect and 
end-windings are included, i.e. 3D-FEA, due to the end-effect leakage and stator flux-leakage, which results in lower eddy current and therefore lower losses [23-24].

\section{Windage Losses}

In the air gap, windage losses occur when two surfaces moving in relation to each other [25]. One of the undesirable effect of windage losses is the drag forces on the rotating components (i.e. rotor), due to the high viscous friction, which produce additional friction torque [26]. In addition, the viscous friction between fluid and rotating part generates heat, which will increase the temperature on the rotor surface [27].

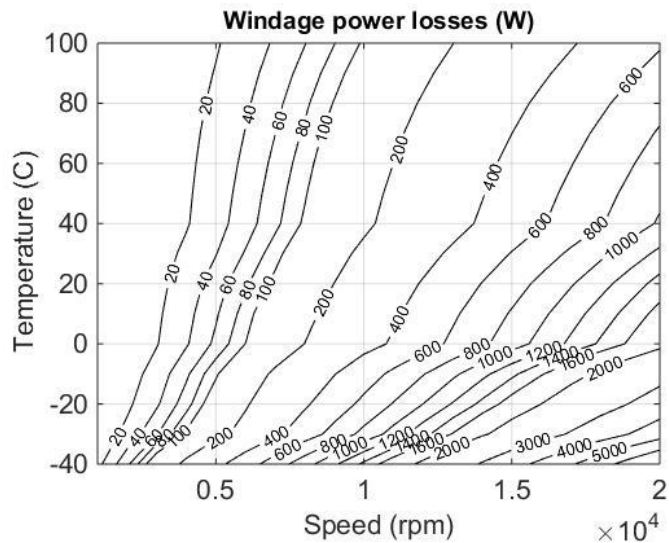

(a)

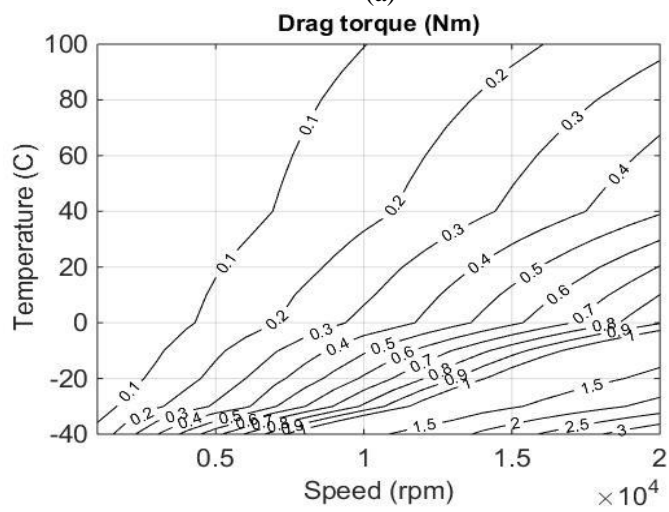

(b)

Fig. 16. Analytically predicted windage losses (a) and drag torque (b) as function of both cooling oil temperature and rotor speed.

For this application, the machine is cooled by the oil coming from the compressor with limited flow rate and high pressure. The whole rotor is immersed in oil and cooled by the oil flow through the gap. The windage losses in the airgap can be defined as shown in [28], where, $\mathrm{K}$ is the roughness coefficient and for smooth surfaces $\mathrm{K}$ is 1 and for axially slotted surfaces is $2.5, \rho$ is the mass density of fluid, $\omega$ is the angular velocity, 1 is the axial length of the rotor, $r$ is the rotor radius, $\delta$ is the airgap length and $R_{e_{\delta}}$ is the Reynold number [28]. The friction coefficient $C_{f}$ depends on many factors and it is often empirically determined [28].

$P_{f}=K C_{f} \pi \rho \omega^{3} r^{4} l$

Where

$$
\begin{array}{ll}
C_{f}=0.515\left[\left(\delta / r_{1}\right)^{0.3} / R_{e_{\delta}}^{0.5}\right] & \left(500<R_{e_{\delta}}<10^{3}\right) \\
C_{f}=0.0325\left[\left(\delta / r_{1}\right)^{0.3} / R_{e_{\delta}}^{0.2}\right] & \left(500<R_{e_{\delta}}<10^{3}\right)
\end{array}
$$

By using (4), the windage losses are determined for several oil temperatures (i.e. from $-40^{\circ} \mathrm{C}$ to $100^{\circ} \mathrm{C}$ ) and rotor speeds (i.e. up to $20 \mathrm{krpm}$ ). The obtained results are shown in Fig. 16 (a), while the relative drag torque values are reported in Fig. 16 (b). At low temperatures, the cooling oil reveals a significant viscosity value of $3.5 \cdot 10^{-4} \mathrm{~m}^{2} / \mathrm{s}$ at $-40^{\circ} \mathrm{C}$ compared to $3.9 \cdot 10^{-6}$ $\mathrm{m}^{2} / \mathrm{s}$ at $100^{\circ} \mathrm{C}$, which leads to both higher windage losses and higher drag torque. In particular, the drag torque varies from 0.1 $\mathrm{Nm}$ to $3.5 \mathrm{Nm}$, as the operating speed increases from zero to 19 $\mathrm{krpm}$, at the lowest temperature (i.e. $-40^{\circ} \mathrm{C}$ ). Conversely, the variation range of the drag torque becomes narrow (i.e. from zero to $0.3 \mathrm{Nm}$ ), when $100^{\circ} \mathrm{C}$ temperature is considered.

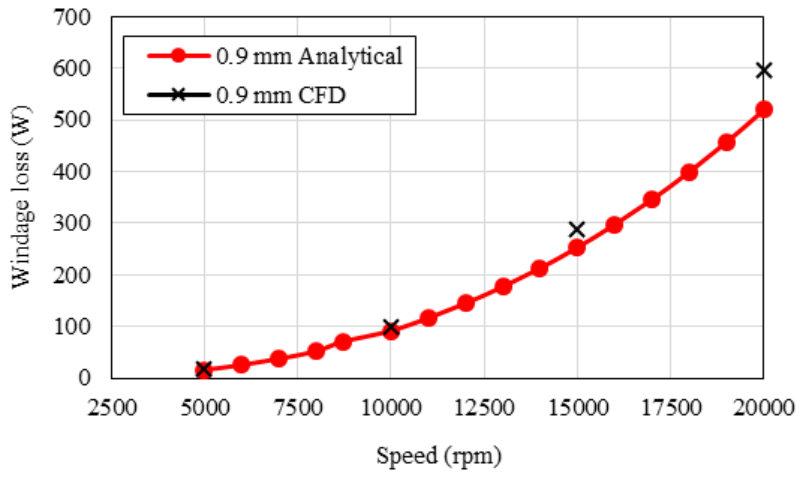

Fig. 17. Comparisons of windage losses predicted by CFD and analytical, when the cooling oil temperature is equal to $90^{\circ} \mathrm{C}$.

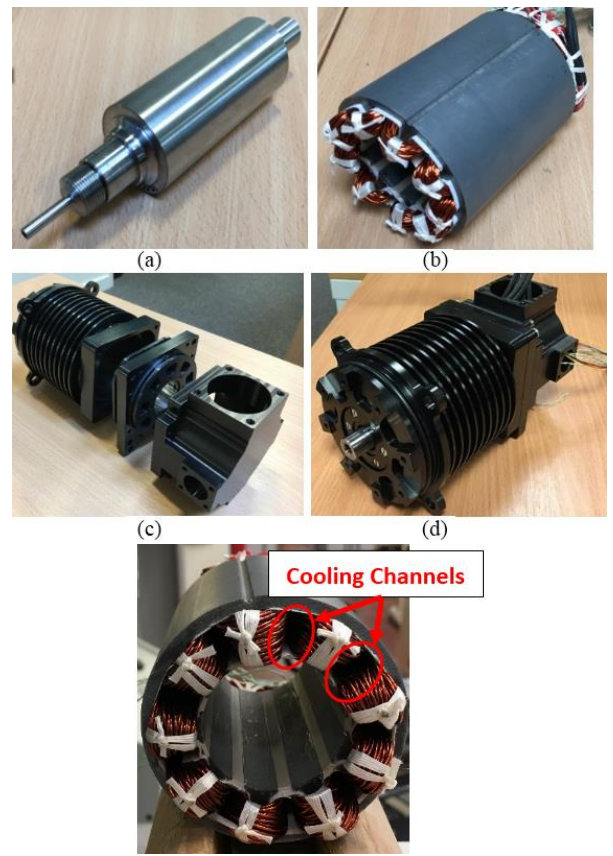

(e)

Fig. 18. PMSM prototype (a) rotor shat with magnets and sleeve (b) stator core with winding (c) housing (d) assembled PMSM and (e) frontal view of stator core highlighting the cooling channels (red circles).

Assuming a cooling oil temperature of $90^{\circ} \mathrm{C}$ (i.e. project specification), the windage losses in the air gap are also predicted using CFD by the commercial software ANSYS Fluent. The comparison between the analytical and numerical results, for $90^{\circ} \mathrm{C}$ cooling oil temperature, is depicted in Fig. 17. A good agreement is found when the rotating speed is lower than $10 \mathrm{krpm}$, however the discrepancy increases as the rotating speed is increased. For the top speed of $19 \mathrm{krpm}$, it is clear that 
the correlation result is about $13 \%$ lower than that obtained by the numerical method.

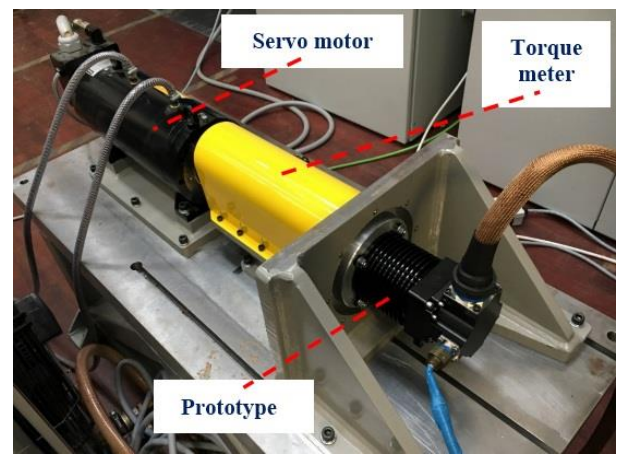

Fig. 19. Experimental test bench.

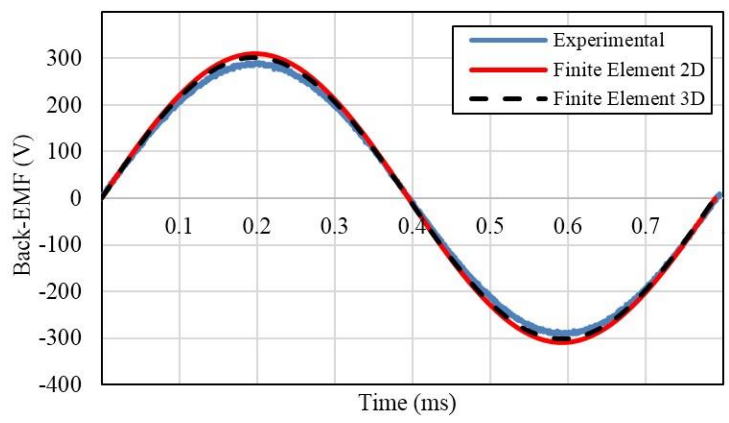

(a)

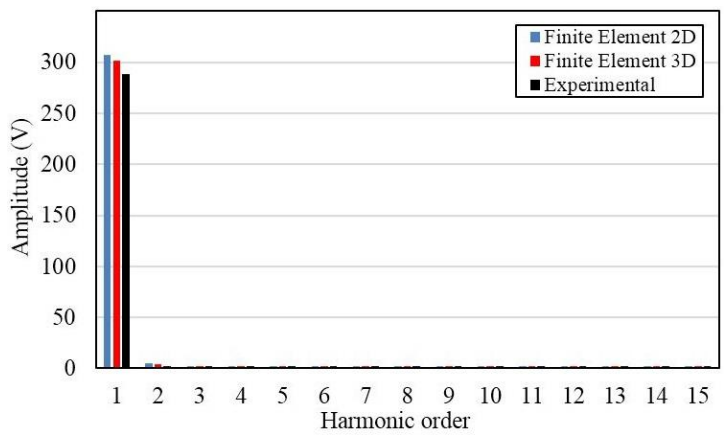

(b)

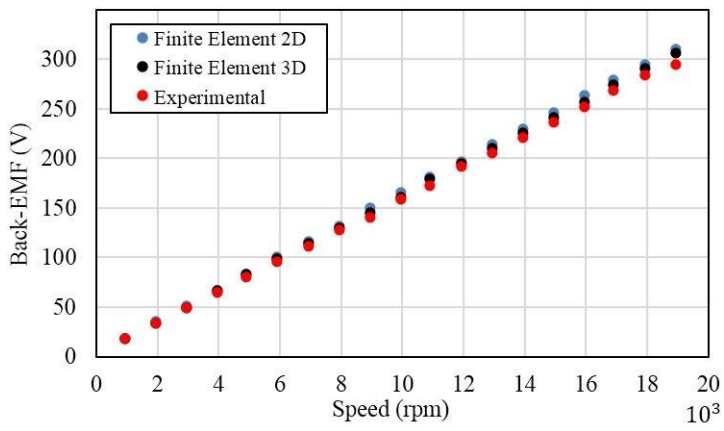

(c)

Fig. 20. The no line to line Back-EMF (a) Waveform at $19000 \mathrm{rpm}$ (b) Harmonic content (c) Back-EMF versus speed.

\section{EXPERIMENTAL TESTS AND RESULTS ANALYSIS}

The low inertia, high power density PMSM has been prototyped and tested. The stator core with windings and cooling channels, the assembled rotor, the housing and the assembled machine are shown in Fig. 18, while the experimental test rig is presented in Fig. 19. An oil cooling system has been used during the experimental tests to dissipate the heat from the entire system. The no load test has been performed to validate the FE simulation and the results are presented in Fig. 20. The measured line to line Back-EMF waveform at the maximum operating speed of $19000 \mathrm{rpm}$ are compared with the one obtained from FE, and the results are reported in Fig. 20 (a) while, the harmonic content is shown in Fig. 20 (b). A good match can be observed between the measured and the calculated Back-EMF waveforms which are sinusoidal as shown in Fig. 20 (a). This is also confirmed by the harmonic content of the measured waveform showing a THD of $1.12 \%$ at $19000 \mathrm{rpm}$ compared to $2.09 \%$ and $2.12 \%$ for the $2 \mathrm{D}$ and 3D FEM, respectively. The voltage constant $K_{v}$ is then calculated based on the experimental test, Fig. 20 (c). The tested results are in good agreement with the $2 \mathrm{D}$ and $3 \mathrm{D} \mathrm{FE}$ simulations, although the measured values of the Back-EMF are slightly low at the maximum speeds with $K_{v} 0.0209 \mathrm{Vs} / \mathrm{rad}$. The obtained $K_{v}$ from measurements are $5.49 \%$ and $3.46 \%$ lower than the one calculated using 2D FEM and 3D FEM, respectively. Fig. 21 shows the measured and the calculated torque as a function of the $I_{q}$ current. Based on the experimental results, the calculated torque constant with only q-axis current applied to the machine $\left(I_{q}=55 \mathrm{~A}, I_{d}=0\right)$ is $0.127 \mathrm{Nm} / \mathrm{A}$ which is $5 \%$ and $2.67 \%$ lower than the values obtained using 2D FEM and 3D FEM simulations, respectively.

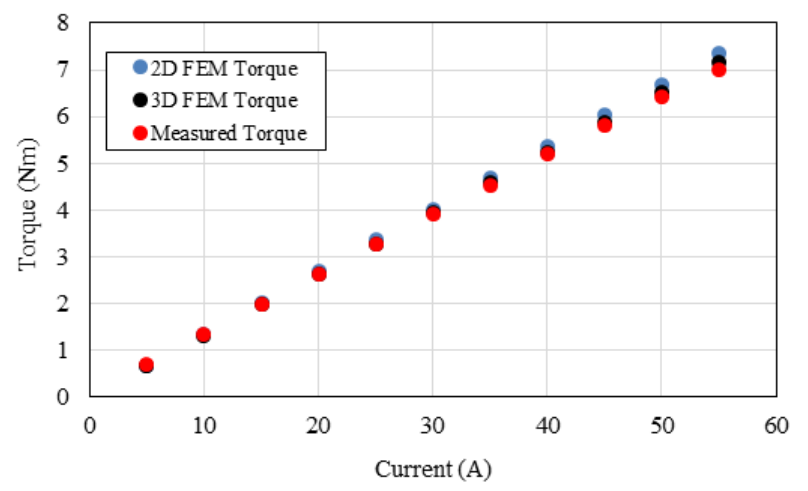

Fig. 21. The measured and calculated torque versus current.

The measured torque is in good agreement with the calculated torque using FEM. A discrepancy is however noted as the current increases, leading to a difference between the measured and calculated torque. This is due to the saturation of the stator laminations which is giving higher flux leakage. Therefore, more accurate results could be achieved using 3D FEM which accounts for the end effects.

\section{CONCLUSION}

This paper presents the design of a high power density PMSM with low moment of inertia and flooded airgap for direct coupled pump applications. The no load and full machine performance are investigated by the 2D and 3D FEM and the output results are compared with experimental results to validate the electromagnetic design. The total losses in the machine including (copper loss, core loss, rotor eddy current loss and windage loss) are predicted and investigated individually.

Considering that the machine under study comprises parallel strands of copper winding, then the discrepancy between the experimental and FE-predicted results of the AC copper loss estimation can be explained by highlighting that the machine 
under study comprises parallel strands of copper winding. The uncontrolled arrangement of the conductors inside the slot of the manufactured machine is very difficult to replicate in the FE software and therefore this has a significant effect on the AC copper loss estimation. The experimental losses vary by $13.6 \%$ when compared to the one obtained using 3D FEM at $1.26 \mathrm{kHz}$.

Also, to reflect the variation in the material properties due to the manufacturing process, the stator core has been experimentally characterized. It is shown that the specific core loss increases drastically when considering data from the measured core as opposed to the material data from its datasheet. In particular, a 23.5\% increase in the stator core loss was observed at the rated operating point of $8700 \mathrm{rpm}$, relative to when the information from datasheet and measured stator core is used. This aspect will be considered in detail in a future publication.

Due to the high harmonic content of the armature field for the machine under study, rotor eddy current losses are also investigated in this work. A segmented configuration has been adopted for the permanent magnet. A high windage losses are observed due to the machine rotation at high speeds with the rotor completely impressed in oil. The built CFD models predicted the windage losses and agreed well with the analytical models.

In particular, for higher performance and higher power density applications, the above aspects need to be considered with more attention to have an accurate estimation of the overall machine performance.

This work has thus indicated and confirmed the effectiveness of the developed techniques used for the proposed high-power density machine which have been verified by experimental measurements of a prototype machine.

\section{ACKNOWLEDGMENT}

This work is supported in part by the Higher Committee for Education Development (HCED) in Iraq.

\section{REFERENCES}

[1] C. Gerada and K. J. Bradley, "Integrated PM Machine Design for an Aircraft EMA," in IEEE Transactions on Industrial Electronics, vol. 55, no. 9 , pp. 3300-3306, Sept. 2008.

[2] C.I. Hill, S. Bozhko, T. Yang, et al. "More Electric Aircraft ElectroMechanical Actuator Regenerated Power Management" in 2015 IEEE International Symposium on Industrial Electronics, pp. 337-342.

[3] Jean-Claude Derrien, Sagem Défense Sécurité, "Electromechanical actuator (EMA) advanced technologies for flight controls", $28^{\mathrm{TH}}$ INTERNATIONAL CONGRESS OF THE AERONAUTICAL SCIENCES.

[4] A. Al-Timimy, M. Degano, P. Giangrande, G. Lo Calzo, Z. Xu, M. Galea, C. Gerada, He. Zhang, L. Xia, "Design and optimization of a high power density machine for flooded industrial pump," 2016 XXII International Conference on Electrical Machines (ICEM), Lausanne, 2016, pp. 14801486.

[5] Z. Xu, A. Al-Timimy, M. Degano, P. Giangrandez, G. Lo Calzo, H. Zhang, M. Galea, et. al., "Thermal management of a permanent magnet motor for a directly coupled pump," 2016 XXII International Conference on Electrical Machines (ICEM), Lausanne, 2016, pp. 2738-2744.

[6] M. Galea, C. Gerada, T. Raminosoa, and P. Wheeler, "Design of a high force density tubular permanent magnet motor," in Electrical Machines (ICEM), 2010 XIX International Conference on, 2010, pp. 1-6.

[7] A. Al-Timimy, P. Giangrande, M. Degano, M. Galea and C. Gerada, "Comparative study of permanent magnet-synchronous and permanent magnet-flux switching machines for high torque to inertia applications," 2017 IEEE Workshop on Electrical Machines Design, Control and Diagnosis (WEMDCD), Nottingham, 2017, pp. 45-51.

[8] P. Ponomarev, M. Polikarpova, O. Heinikainen and J. Pyrhönen, "Design of integrated electro-hydraulic power unit for hybrid mobile working machines," Proceedings of the 2011 14th European Conference on Power Electronics and Applications, Birmingham, 2011, pp. 1-10.

[9] B. C. Mecrow, A.G. Jack, D.J. Atkinson, S.R. Green, G.J. Atkinson, A. King, B. Green, "Design and testing of a four-phase fault-tolerant permanent-magnet machine for an engine fuel pump," in IEEE Transactions on Energy Conversion, vol. 19, no. 4, pp. 671, Dec. 2004.

[10] G. J. Atkinson, B. C. Mecrow, A. G. Jack, D. J. Atkinson, P. Sangha and M. Benarous, "The Analysis of Losses in High-Power Fault-Tolerant Machines for Aerospace Applications," in IEEE Transactions on Industry Applications, vol. 42, no. 5, pp. 1162-1170, Sept.-Oct. 2006.

[11] E. Chiricozzi, M. Tursini, M. Villani and L. Castellini, "An integrated electromechanical actuator for high dynamic pump application," The XIX International Conference on Electrical Machines - ICEM 2010, Rome, 2010, pp. 1-6.

[12] A. Al-Timimy, M. Degano, Z. Xu, G. Lo Calzo, P. Giangrande, M. Galea, C. Gerada, He Zhang, L. Xia, "Trade-off analysis and design of a high power density PM machine for flooded industrial pump," IECON 2016 42nd Annual Conference of the IEEE Industrial Electronics Society, Florence, 2016, pp. 1749-1754.

[13] C. Sciascera, P. Giangrande, C. Brunson, et al., "Optimal design of an electro-mechanical actuator for aerospace application" in 2015 Annual Conference of the IEEE Industrial Electronics Society, 2015.

[14] H. Fang, R. Qu, J. Li, P. Zheng and X. Fan, "Rotor Design for High-Speed High-Power Permanent-Magnet Synchronous Machines," in IEEE Transactions on Industry Applications, vol. 53, no. 4, pp. 3411-3419, July-Aug. 2017.

[15] F. Jiancheng, L. Xiquan, B. Han and K. Wang, "Analysis of Circulating Current Loss for High-Speed Permanent Magnet Motor," in IEEE Transactions on Magnetics, vol. 51, no. 1, pp. 1-13, Jan. 2015.

[16] M. van der Geest, et al. "Stator winding proximity loss reduction techniques in high speed electrical machines," 2013 International Electric Machines \& Drives Conference, Chicago, IL, 2013, pp. 340-346.

[17] M. Galea, C. Gerada, T. Raminosoa and P. Wheeler, "A Thermal Improvement Technique for the Phase Windings of Electrical Machines," in IEEE Transactions on Industry Applications, vol. 48, no. 1, pp. 79-87, Jan.-Feb. 2012.

[18] R. Wrobel, A. Mlot and P. H. Mellor, "Contribution of End-Winding Proximity Losses to Temperature Variation in Electromagnetic Devices," in IEEE Transactions on Industrial Electronics, vol. 59, no. 2, pp. 848857, Feb. 2012.

[19] C. Sciascera, M. Galea, P. Giangrande, et al., "Lifetime consumption and degradation analysis of the winding insulation of electrical machines" in 2016 IET International Conference on Power Electronics Machines and Drives, April 2016.

[20] Ahmed Al-Timimy, Gaurang Vakil, Michele Degano, Paolo Giangrande, Chris Gerada and Michael Galea, "Considerations on the Effects that Core Material Machining has on an Electrical Machine's Performance," in IEEE Transactions on Energy Conversion, vol. PP, no. 99, pp. 1-1. doi: 10.1109/TEC.2018.2808041.

[21] M. Galea, L. Papini, H. Zhang, C. Gerada and T. Hamiti, "Demagnetization Analysis for Halbach Array Configurations in Electrical Machines," in IEEE Transactions on Magnetics, vol. 51, no. 9, pp. 1-9, Sept. 2015.

[22] C. Sciascera, P. Giangrande, L. Papini, et. al., "Analytical Thermal Model for Fast Stator Winding Temperature Prediction", in IEEE Transactions on Industrial Electronics, vol. 64, n. 8, pp. 6116-6126, March 2017.

[23] A. Al-Timimy, M. Alani, M. Degano, et al. "Influence of Rotor Endcaps on the Electromagnetic Performance of High Speed PM Machine" IET Electric Power Applications, 2018.

[24] P. Giangrande, F. Cupertino and G. Pellegrino, "Modelling of linear motor end-effects for saliency based sensorless control", in 2010 IEEE Energy Conversion Congress and Exposition, 2010.

[25] Bruckner, Robert J. "Windage power loss in gas foil bearings and the rotor-stator clearance of high speed generators operating in high pressure environments." ASME Turbo Expo 2009: Power for Land, Sea, and Air. American Society of Mechanical Engineers, 2009.

[26] Etemad, M. R., et al. "Evaluation of windage losses for high-speed disc machinery." Proceedings of the Institution of Mechanical Engineers, Part A: Journal of Power and Energy 206.3 (1992): 149-157. 
[27] Huynh, Co, Liping Zheng, and Dipjyoti Acharya. "Losses in high speed permanent magnet machines used in microturbine applications." Journal of engineering for gas turbines and power 131.2 (2009): 022301.

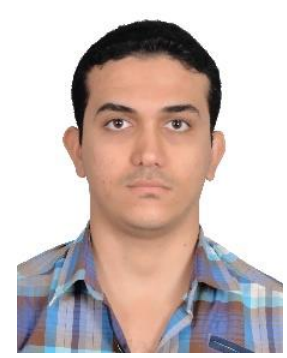

Ahmed Al-Timimy received his M.Sc. degree in Electrical Engineering from the University of Technology, Baghdad, Iraq in 2012. He is currently working towards his $\mathrm{PhD}$ in electro-magnetic modelling and electrical machine design within the Power Electronics, Machines and Control (PEMC) Group at The University of Nottingham, Nottingham, UK. His main research interests are design and analysis of high performance electrical machines for aerospace applications.

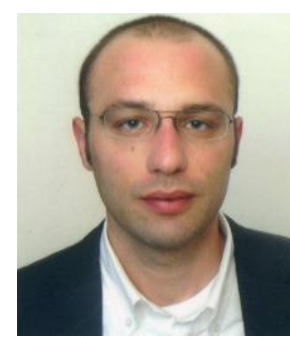

Paolo Giangrande was born in Monopoli, Italy, in March 1982. He received his $\mathrm{PhD}$ in electrical engineering at the Technical University of Bari in 2011. During 2008 he was a Marie Curie IntraEuropean Fellow at the University of Malta. Since January 2012, he is Research Fellow at the University of Nottingham within the PEMC group. His research interests include sensorless control of $\mathrm{AC}$ electric drives and intelligent motion control, as well as design, modeling and parameters identification of electrical machine for aerospace application.

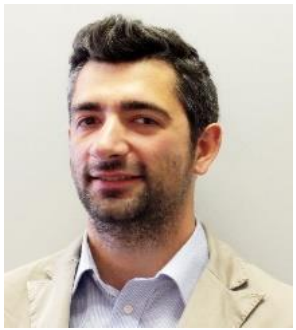

Michele Degano (M'15) received the Laurea degree in electrical engineering from the University of Trieste, Trieste, Italy, in 2011, and the $\mathrm{Ph} . \mathrm{D}$. degree in industrial engineering from the University of Padova, Padova, Italy, in 2015. During his doctoral studies, he cooperated with several local companies for the design of permanent-magnet machines. In 2015, he joined the Power Electronics, Machines and Control Group, The University of Nottingham, Nottingham, U.K., as a Research Fellow, where he is currently an Assistant Professor teaching advanced courses on electrical machines. His main research interests include design and optimization of permanent-magnet machines, reluctance and permanent-magnet-assisted synchronous reluctance motors through genetic optimization techniques, for automotive and aerospace applications, ranging from small to large power.

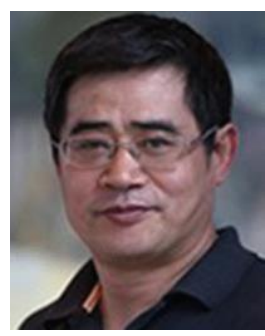

Zeyuan Xu received the Ph.D. degree in mechanical engineering from the University of Manchester, Manchester, U.K., in 2002.He subsequently worked as a Research Fellow at UMIST, Brunel University, and the University of Nottingham. He is currently a Senior Research Fellow in thermo-mechanical design of high speed electrical machines within the PEMC group at the University of Nottingham, Nottingham, U.K. His main research interests include turbulent thermo-fluid flow, heat transfer enhancement, and thermal management of advanced electrical machines and power electronics.

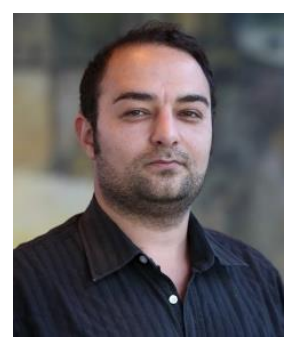

Michael Galea (M'13) received his $\mathrm{PhD}$ in electrical machines design from the University of Nottingham, UK, where he has also worked as a Research Fellow. He is currently the Head of the School of Aerospace in the University of Nottingham, Ningbo, China, where he is also the Director of Aerospace. He is also the Deputy Director of the Institute for Aerospace Technology in the University of Nottingham, UK. He currently lectures in Electrical Drives and in Aerospace Systems Integration and manages a number of diverse projects and programmes related to the more / all electric aircraft, electrified propulsion and associated fields. His main research interests are
[28] J. Saari, "Thermal analysis of high -speed induction machines", ACTA Polytechnica Scandinavia, Electrical Engineering Series No. 90, Helsinki $1998.73 \mathrm{p}$

design, analysis and thermal management of electrical machines and drives, the more electric aircraft and electrified and hybrid propulsion.

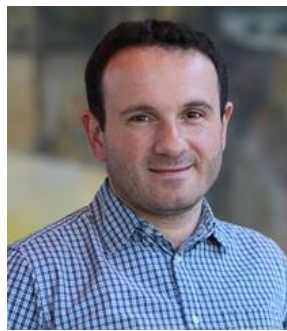

Chris Gerada (M'05-SM'12) received the Ph.D. degree in numerical modelling of electrical machines from The University of Nottingham, Nottingham, U.K., in 2005. He was a Researcher with The University of Nottingham, working on high-performance electrical drives and on the design and modelling of electromagnetic actuators for aerospace applications. Since 2006, he has been the Project Manager of the GE Aviation Strategic Partnership. In 2008, he became a Lecturer in electrical machines, in 2011, as an Associate Professor, and in 2013, a Professor at The University of Nottingham. His main research interests include the design and modelling of high-performance electric drives and machines. Prof. Gerada serves as an Associate Editor for the IEEE TRANSACTIONS ON INDUSTRY APPLICATIONS and is the Chair of the IEEE Industrial Electronics Society Electrical Machines Committee.

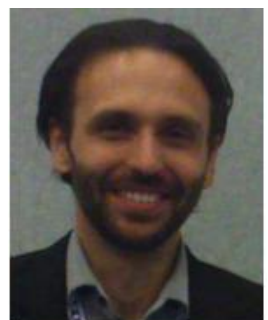

Giovanni Lo Calzo received the M.S. degree in electronic engineering, and the Ph.D. degree in mechanical and industrial engineering from Roma Tre University, Rome, Italy, in 2010 and 2015, respectively. From 2010 to 2011, he was a Research Assistant at Roma Tre University. From 2011 to 2017, he was a Research Fellow in the Power Electronics, Machines, and Control Group, University of Nottingham, Nottingham, U.K. He is currently a Senior Power Electronic Design Engineer with Dyson, Malmesbury, U.K. His research interests include power electronics converters for high-speed machines, control, and modelling of grid-tied and isolated inverters, and output filter topologies.

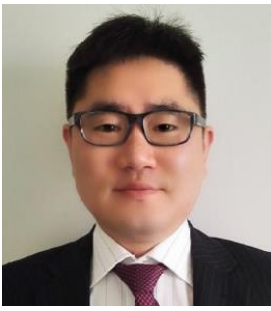

He Zhang (M'14) received his B.Eng. degree from Zhejiang University, China, in 2002. He obtained the $\mathrm{Ph} . \mathrm{D}$. degree in electrical machines from The University of Nottingham, U.K, in 2009. Then he joined the UK Water Research Centre, Swindon, U.K., and worked on energy efficiency determination for motor drive system for two years. He is currently a Principal Research Fellow and Director of Best motion machine drive technology center within the Power electronics, Machines and Control research group in University of Nottingham. His research interests include high performance electric machines and drives.

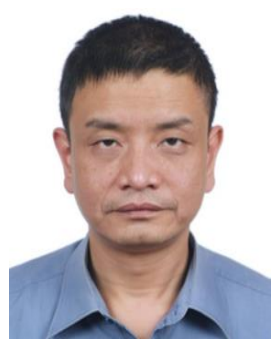

Liqun Xia was born in May 1968. He graduated from the Department of fluid transmission and control of Beijing Institute of Technology in 1990. He received a master's degree and a doctorate in Northwestern Polytechnical University in 2001 and 2009. He is now an actuation system chief engineer of FACRI. His research interests include hydraulic 